\title{
The Integrated Development Strategy of Coastal Industrial Areas and City Based on Underground Space Development
}

\author{
Feng Shao $\mathbb{D}$, Pingyang Shi $\mathbb{D}$, Yusheng Ding $\mathbb{D}$, and Ce Dong $\mathbb{C}$ \\ College of Architecture and Urban Planning, Qingdao University of Technology, Qingdao, Shandong 266033, China \\ Correspondence should be addressed to Feng Shao; 3411376@qq.com
}

Received 1 June 2021; Revised 7 July 2021; Accepted 13 August 2021; Published 27 August 2021

Academic Editor: Zhijie Wen

Copyright (C) 2021 Feng Shao et al. This is an open access article distributed under the Creative Commons Attribution License, which permits unrestricted use, distribution, and reproduction in any medium, provided the original work is properly cited.

\begin{abstract}
As a crucial node of Qingdao's construction of a modern international metropolis, a topnotch marine port, a demonstration zone for local economic and trade cooperation of the Shanghai Cooperation Organization (SCO), and an international shipping trade financial innovation center, the Qingdao Cruise Port warrants transformation to adapt to the future development of Qingdao city. Besides, with the constant increase in the intensity of urban underground space (UUS) development in Qingdao, the organic integration of underground space reconstruction and urban development in the cruise port area must be accentuated. Taking the underground space development project in Qingdao Cruise Port as the background, this study analyzes the multidimensional development and utilization of underground space in the project (the functional distribution of the two-dimensional plane and the stereo integration of the three-dimensional space). In addition, this study explores strategies to promote the organic integration of industrial areas and cities through underground space development. Expanding the research field of UUS, this study provides reference cases for the transformation of old industrial areas in other coastal cities.
\end{abstract}

\section{Introduction}

Industrial areas play a vital role in promoting the development of cities. However, with the development of cities, some industrial areas have slowly lost their original functions and are on the verge of being eliminated. Nevertheless, these old industrial areas occupy key geographical locations in cities, which have unique values. Thus, the research on the transformation of old industrial areas has become a hot topic in the architecture field. Meanwhile, to relieve the pressure of urban development, the development of urban underground space (UUS) has been increasingly focused upon because of its advantages of efficient use of land resources, high security, energy conservation, and environmental protection. Developing UUS is a critical way to build green and sustainable cities [1]. At present, people's research on UUS involves underground space planning, underground engineering, and sustainable development. With the development of cities and the transfer of urban industries, some industrial areas have been abandoned. These industrial areas require underground space development. The current research on underground space in industrial areas involves design principles [2], planning strategies [3], technological development [4], and development scale forecast [5]; however, the research on underground space in industrial areas and urban development factors is marginally scarce. Relatively limited research has been conducted on the correlation between the underground space of industrial zones and the elements of urban development. Thus, the exploration of related fields is warranted.

\section{Status Quo of Research on Underground Space}

2.1. Foreign Research on Underground Space. The Associated Research Centers for Urban Underground Space (ACUUS) conference is an international academic conference on UUS research. The theme of each conference reflects the current international research hotspots in the field of UUS. To date, 17 sessions of the ACUUS conference have been held. Initially, the conference focused on the advantages, structure, form, and development prospects. Later, the 
theme gradually shifted to the fields of underground space and planning, resources, economy, and environment. As the research progressed in the field, the themes of recent ACUUS conferences focused on the use of underground space development to attain sustainable urban development (Table 1).

2.2. China's Research on Underground Space. China's research on underground space has borrowed significantly from foreign advanced experience. "Comprehensive Utilization of Underground Space" published by a foreign magazine translated by Liantai [6] opened the gate to the research of underground space in China. Subsequently, Bihua [7] and $\mathrm{Xu}$ [8] learned a lot from foreign experience and start researching on related fields based on the actual situation in China. However, most research during this period focused on the fields of underground building design and underground space planning, rendering the research field incomprehensive. At the end of the twentieth century, Qihu [9] and Linxu [10] not only further researched underground space planning and design but also keenly captured the key and challenging issues of China's development. In addition, they started combining underground space development with urban development. The development of underground space is a necessary condition for the realization of sustainable urban development. After entering the new century, China's research on UUS has gradually diversified. Yu et al. [11] discussed the overall planning, detailed planning, and planning management process of UUS. Xu et al. [12] discussed the impact of economic factors on the development of underground space, claiming that different stages of economic development exerted different effects on the development of UUS. As the economy continues to improve, the proportion of underground transportation and underground municipal facilities will increase gradually. Hong and Shen [13] combined the evolution process of underground space functions worldwide and the research context of international underground space design theory. The authors proposed forward a requirement for the development of China's underground space (establishment of the discipline of underground architecture) and elucidated two trends therein (the stereo development of buildings, combined development of underground transportation space and urban space). In addition, Zhu et al. [1] summarized China's current planning and management status and examined the corresponding policies and laws for UUS development; they believed China's UUS has a bright future, but further coordination is warranted in planning. In formulating policies and regulations, it is essential to articulate corresponding implementation policies, laws, and regulations in compliance with national conditions. Wang et al. [14] and Ya and Chengli [15] comprehensively analyzed the crowd psychology in the underground space and claimed that people's negative impression of the underground space is objective. The study of crowd psychology in underground space is a crucial means to augment the environmental quality of underground space. Meanwhile, with the continuous furthering of China's green development concept, the use of underground space to assist the green development of society has garnered growing attention, and the research enthusiasm for underground energy systems, underground water storage systems, underground logistics systems, and underground expressways has been increasing every year. Furthermore, the development and research of China's underground space are moving gradually toward world-class standards.

\subsection{Limitations in UUS Research}

2.3.1. Lack of Research on Urban Fringe Areas. An all-round and multilevel development of cities has created many new urban problems. The research on UUS should be conducted from the perspective of architectural disciplines such as promoting urban development by analyzing and solving practical problems. The current research on UUS still concentrates on the areas of urban pedestrian streets, urban complexes, urban rail transit, and civil air defense engineering; most of these research fields are located in urban central areas, and the pressure on urban land is high. Thus, corresponding research is urgently needed to expand the prospect of UUS development. However, research on the development of underground space in the fringe areas of urban development, such as old industrial areas and historic preservation blocks, is deficient. China's urban development is gradually shifting from incremental construction to stock renewal. Perhaps, research on UUS in low-stress areas could effectively extend the space for urban development, and it has great significance to the realization of urban green and sustainable development.

\subsubsection{Lack of Research Related to Urban Development} Factors. The pressure on urban development is increasing gradually, and the development and utilization of UUS as one of the critical ways to relieve the pressure of urban development has been broadly recognized and concerned. Currently, the research hotspots of UUS still focus on exploring underground space, underground environment, underground function, and other UUS utilization forms. The research overlooks investigating the elements of UUS that affect urban development, how underground space affects urban development elements, and the complex correlation between underground space and urban development elements. Of note, the discussion on the correlation between urban development factors and UUS development can enable people to find the fundamental "key point" for UUS development to promote urban development, as well as analyze the size of the driving force that promotes urban development during underground space development. Moreover, investigating the correlation between UUS and urban development elements could help people use new research perspectives to analyze underground space, expand the assessment methods of underground space development and utilization, help enhance the overall quality of underground space, and promote sustainable development of cities.

\section{Elements of Urban Development}

The elements of urban development, including population, economic activities, public resources [16], land [17], and science and technology [18], are the elementary conditions 
TABle 1: Past conferences of ACUUS.

\begin{tabular}{lccc}
\hline Session & Time & Location & Conference theme \\
\hline 1 & 1983 & Sydney, Australia & Energy Efficient Buildings with Earth Shelter Protection \\
2 & 1986 & Minneapolis, United States & Advances in Geotectural Design \\
3 & 1988 & Shanghai, China & New Developments of Underground Space Use \\
4 & 1991 & Tokyo, Japan & Urban Underground Utilization \\
5 & 1992 & Delft, Netherlands & International Conference on Underground Space and Earth Sheltered Structures \\
6 & 1995 & Paris, France & Underground Space and Urban Planning \\
7 & 1997 & Montreal, Canada & Underground Space: Indoor Cities of Tomorrow \\
8 & 1999 & Xi'an, China & Agenda and Prospect of the Underground Space for the Turn of the Century \\
9 & 2002 & Turin, Italy & Urban Underground Space: A Resource for Cities \\
10 & 2005 & Moscow, Russia & Underground Space: Economy and Environment \\
11 & 2007 & Athens, Greece & Underground Space: Expanding the Frontiers \\
12 & 2009 & Shenzhen, China & Using the Underground of Cities: For a Harmonious and Sustainable Urban Environment \\
13 & 2012 & Singapore, Singapore & Underground Space Development-Opportunities and Challenges \\
14 & 2014 & Seoul, Korea & Underground Space: Planning, Administration, and Design Challenges \\
15 & 2016 & Saint Petersburg, Russia & Underground Urbanisation as a Prerequisite for Sustainable Development \\
16 & 2018 & Hong Kong, China & Integrated Underground Solutions for Compact Metropolitan Cities \\
17 & 2021 & Helsinki, Finland (online) & Deep Inspiration \\
\hline
\end{tabular}

Source: https://www.acuus.org/index.php/past-conferences/complete-list.

affecting urban development and the causes of urban generation, change, and development.

The five elements of urban development, which constitute the urban development model in the form of a pyramid (Figure 1), are the fundamental constituent units of modern urban development and conjointly promote urban development. As the fundamental element of urban development, the population is at the bottom of the pyramid to support the other four elements. Land and economic activities constitute the two core elements of urban development, which provide urban physical activity space and urban economic activity space for the urban population, respectively. In addition, they provide physical construction space and construction funds for public resources. As a crucial element of urban development, public resources inherit the population, land, and economic activities. The factors provide a platform for technological development. As the top element, technology is equally affected by the other four elements and, at the same time, provides feedback on other elements. Technology is progressively becoming a core element influencing urban development. The five elements of a city interact with each other. To accomplish the sustainable development of a city, it is essential to ensure a balanced and stable development among the five elements of population, land, economic activities, infrastructure, and science and technology.

\section{Project Overview of Qingdao Cruise Port Starting Area}

As a key node of Qingdao's construction of a modern international metropolis, an outstanding marine port, a demonstration zone for local economic and trade cooperation of the Shanghai Cooperation Organization (SCO), and an international shipping trade financial innovation center, the Qingdao Cruise Port warrants transformation to adapt to the future development of Qingdao city. The starting area (Figure 2) project of the cruise port inherits the historical memory of Qingdao and reshapes the physical space of the port area to introduce new industries and new forms of business [19]. In addition, the starting area can provide a new growth engine for the development of Qingdao. Second, the program opened the development process of Qingdao as a world ocean city, acting as a link between the entire cruise port area and the development process of Qingdao.

4.1. Controlled Detailed Planning of the Starting Area. The controlled detailed planning of the project in the starting area transformed the port into commerce, culture, tourism, and parks, while reserving the residential land. In the project, the existing storage facilities will be rebuilt to complete the replacement of commercial, residential, entertainment, and leisure functions in the old industrial zone and then build the Qingdao cultural tourism area as the core of the starting area through new buildings. Besides, the coastal parks will connect cultural and tourist areas, business areas, shopping areas, distribution centers, docks, and residential areas, building a "port-city" integration corridor to connect the city, port, and ocean. In addition, the project will make the "city-port-sea" a connection to bridge the current situation of separation between old industrial areas and urban areas and improve the spatial quality of Qingdao's old urban areas (Figure 3).

\section{Underground Space Promotes the Integrated Development of Industrial Zones and Cities}

With the change of the urban development mode and the growth of emerging industries, especially the technology 


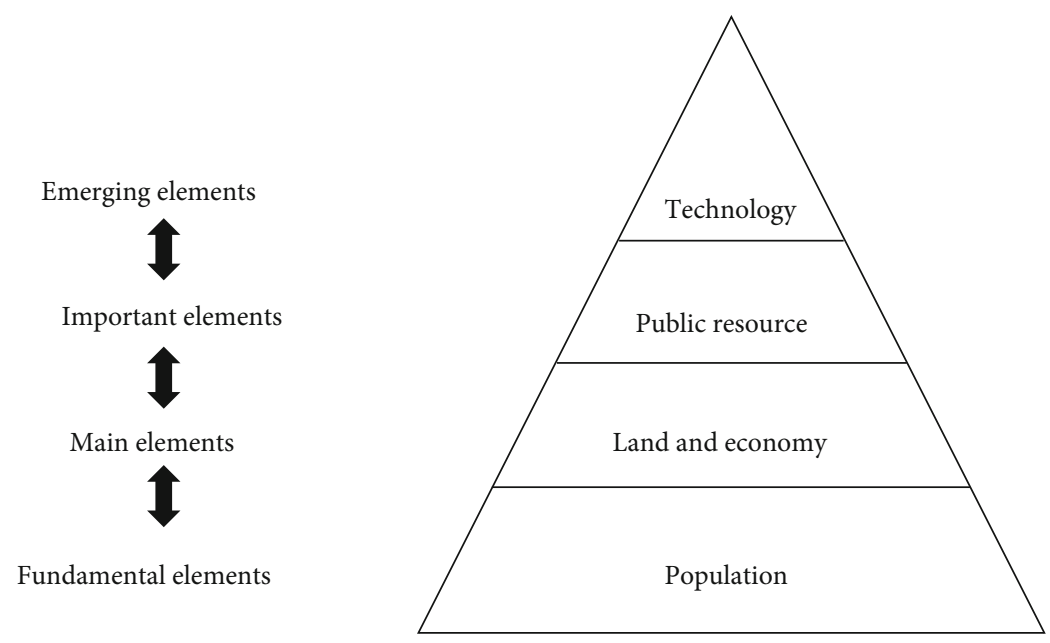

Figure 1: Pyramid of urban development factors (source: self-created).

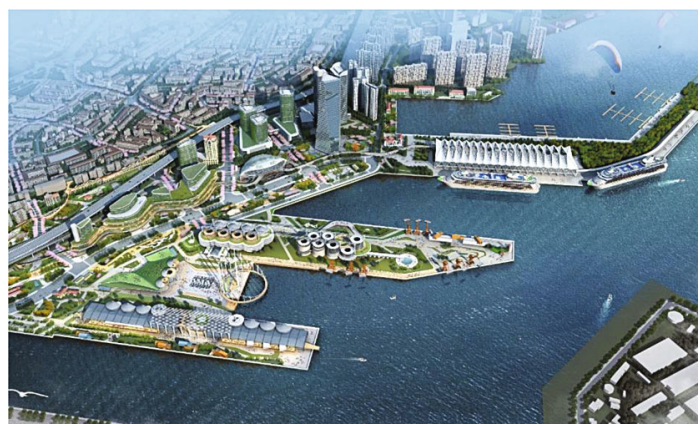

Figure 2: The rendering of Qingdao Cruise Port starting area (source: from the Internet).

industry, many industrial areas have not fulfilled the requirements of the times, as they are faced with the dilemma of being eliminated and abandoned [20]. The lack of attractiveness of old industrial areas leads to the loss of population in the region, which passively results in the lack of economic activity in this region and decreases the motivation for investment and construction of public resources. The vicious circle of the loss of population, reduction in economic activities, and the lack of public resources results in the continuous decline of the industrial zone. However, the industrial zone has considerable idle land, which can make the positive cycle of attracting population, promoting economic activities, optimizing the allocation of public resources, and attracting high-tech industries through the underground space development; this then aggregates the five elements of population, land, economic activities, public resources, and science and technology to promote the development of the city.

5.1. Create a Vibrant Space Area to Attract the Urban Population and Stimulate Economic Activities. The core of space vitality is people who engage in various activities. The physical space provides people with a place for activities, which certainly affects people's activities [21]. In the overall planning of the underground space of the Qingdao Cruise
Port launch area, a large underground pedestrian has been designed. Besides, cultural, entertainment, and commercial functions have been placed on both sides of the pedestrian system, thereby making a multiple plan function to break the traditional monotonous functional organization of the underground space. In addition, the three-dimensional pedestrian system has been used to connect the businesses, subways, and other functions in the three-dimensional space (Figure 4), which will promote the three-dimensional integration of urban, port, underground, and coastal areas, as well as create a systematic and coherent integration of stereo space. Reportedly, the urban vitality space sweeps the attraction of the urban population [22]. Meanwhile, in the underground space plan of the starting area, business centers, distribution centers, subways, exhibitions, culture, entertainment, hotels, and other commercial functions are connected in series through the underground pedestrian system (Figure 5). The connection forms a unified and complete underground commercial facility, stimulating the economic activity to the greatest extent. Underground commerce cannot exist in isolation. Thus, the underground commerce and related functions have been rationally planned in the vertical space, so that underground commerce and related functions on the ground form a synergy to create economies of scale [23].

5.2. Promote Efficient Use of Land. Modern cities are developing in the direction of centralized and intensive use of functions and space; however, the development of cities has not amended the urban environment [24]. As an emerging first-tier city, Qingdao is also fronting the shortage of land resources like other first-tier cities such as Beijing, Shanghai, Guangzhou, and Shenzhen. Through underground space development, multilevel modern urban space can be created to improve urban functions and the environment. In addition, creating a living space full of bright light and green areas on the ground provides residents with a peaceful and comfortable experience, while using underground space to accommodate urban functions [24]. The project advocates the function of underground space in the 


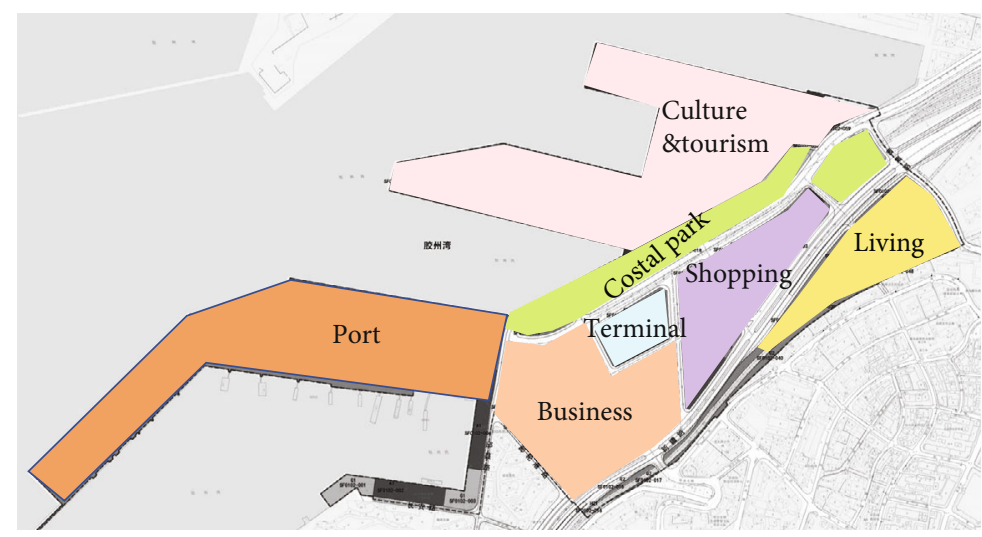

(a)

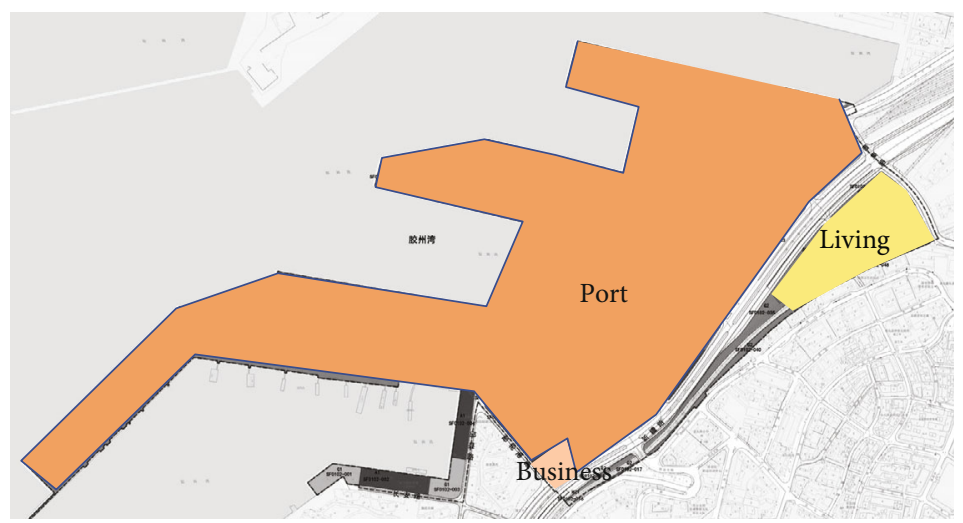

(b)

Figure 3: (a) The current land use map; (b) the land use planning map (source: self-created per the relevant information).

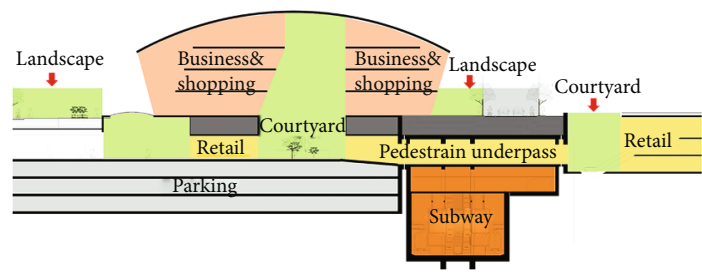

FIGURE 4: Stereoscopic walking system (source: self-created per the relevant information).

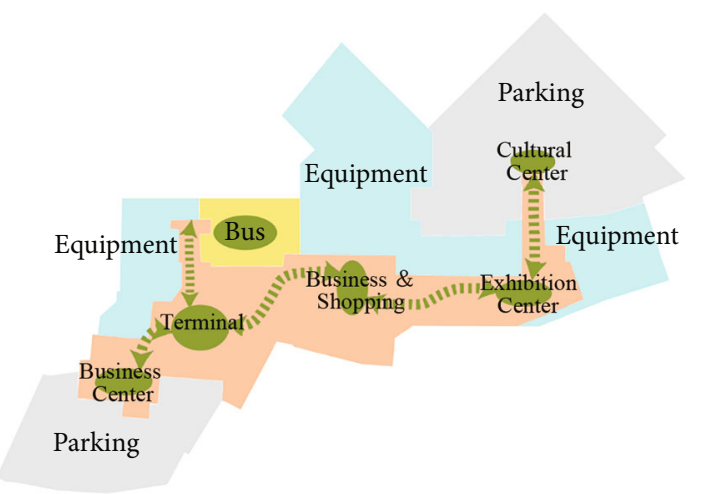

FIGURE 5: The underground walking system connects each functional node (source: self-created per the relevant information). vertical commercial space area, such as subways, parking, underground walking area, and integrated pipe gallery (Figure 6), which has increased the development intensity of the unit land space and opened up more development space for the city.

5.3. Provide New Space for the Construction of Public Resources. The development of underground space enables more effective use of urban public resources [24]. Different public resources exert different impacts on urban development. For instance, urban elevated roads affect people's perception of the city, while the landscape will enhance the urban environment, which, in turn, promotes the enhancement of the commercial value around the green space. The development of underground space provides a new construction space for public resources with negative attributes (Figure 7). The development of UUS is the most effective way to increase the land utilization rate, save land resources, ease the density of central cities, and decrease environmental pollution [25]. The municipal integrated pipe gallery in the starting area is buried in the shallow underground space under the urban landscape, reserving a flexible development space to reserve space for urban development. Meanwhile, it provides significant green construction land for the city. By constructing high-quality coastal parks, the city will be a landmark of the Jiaozhou Bay, strengthening the positive role of public resources. In the starting area project, the 


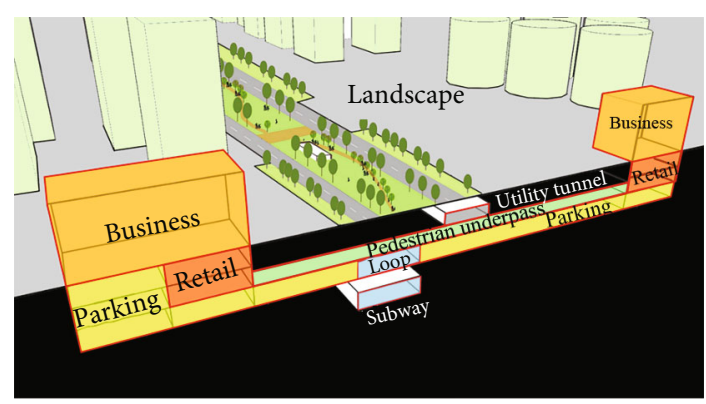

Figure 6: Stereo planning of underground space (source: self-created per the relevant information).

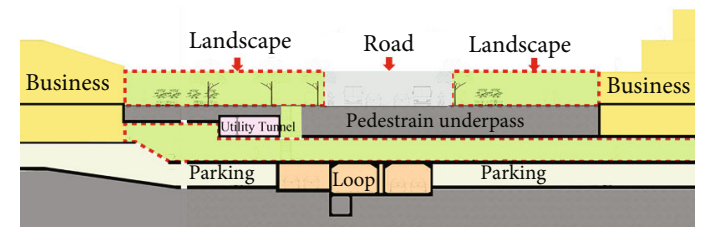

FIGURE 7: Development form of public resources of underground space (source: self-created per the relevant information).

underground space is comprehensively planned in three dimensions. A regional car loop is built underground to build an efficient and convenient underground train layer. Vehicle leveling and pedestrian leveling are separated in the vertical space to realize the diversion of people and vehicles, passengers and cargo, and arrival and departure transit.

5.4. Provide a New Application Environment for Technological Innovation. High-tech technologies represented by $5 \mathrm{G}$, big data, and artificial intelligence (AI) are becoming one of the main driving forces for urban development. As China's economic development enters "new times," the construction of smart cities supported by technological innovation has been upgraded [26]. While developing the underground space of old industrial buildings and industrial facilities, a combination of parameterization and AI is used to keep the physical environment such as indoor sound, light, and heat in a stable state through computer control; this can ensure a good living environment while avoiding energy waste. In the underground pedestrian system, underground vehicle transportation system, and underground parking, big data combined with 5G technology can be used to broadcast traffic conditions in real time while also effectively forecasting traffic conditions, so that people can plan travel plans reasonably.

\section{Strategy of Industrial Transformation and Urban Integrated Development Based on Underground Space Development}

Sustainable development should be considered a crucial criterion for the development of underground space [27]. Urban historical and cultural heritage is the foundation of sustainable urban development, a valuable resource for urban development and a key component of the development of the knowledge economy [28]. As an integral part of the historical and cultural heritage of industrial cities, the transformation of industrial areas is the only way to adapt to future urban development; it is also an effective way to preserve urban memory and an urgent task to attain stock renewal. As a special transformation method, the underground space development in the industrial zone has the advantages of increasing land utilization and greening rate, protecting the memory and context of the city, and promoting the three-dimensional development of the city. However, promoting the transformation of industrial areas and urban integrated development per the development of underground space warrants appropriate strategies.

6.1. Development of the Whole Society under the Guidance of Government. The investment in the construction of UUS is substantial [29]. The investment return period of projects is usually longer, and the capital requirements are high. Under typical circumstances, estate developers stay away from such projects. At the moment, it is crucial for the government to lead the development of underground space in the industrial zone by formulating relevant policies and regulations and even acting as the main funder of the project. Through the traction of the government, all parties in the society are gathered for development and construction. In addition, the government should encourage developers to invest in construction independently and provide specific policy support; however, the government should strictly regulate the development and construction plan to ensure the project's quality. Moreover, universities and other scientific research institutions should conduct standardized research on the development standards of underground space in industrial areas. By standardizing the development of underground space in industrial areas, scale effects can be realized and development costs further saved. As the direct participants of development, the public should also present reasonable opinions and suggestions, participate in the development and construction from the first-person perspective, and discuss what type of underground space people need to attain the purpose of enhancing the quality of underground space.

6.2. Demonstration of the Necessity and Feasibility of Underground Space Development in Industrial Areas. Although underground space is a considerable and abundant space resource [30], not all industrial zone transformations need the development of their underground space. Thus, the necessity and feasibility of developing the industrial zone's underground space should be illustrated by demonstrating the project's impact on the city's economy, environment, and humanities. In addition, a comprehensive evaluation should be done to determine whether the industrial zone's underground space needs to be developed and utilized during the transformation. Relevant universities and other scientific research institutions can establish a model of the necessity and feasibility of underground space development by exploring the development of the underground space in industrial areas, economics, environment, and context. Furthermore, the model can be used to determine whether the underground space in industrial areas 
needs to be developed and realize the standardized development of the underground space.

\subsection{Multidimensional Development of the Underground} Space in Industrial Areas. The multidimensional development of the underground space in industrial areas has four dimensions. (i) The two-dimensional level includes the reasonable layout of the underground space functions per urban development needs; the integration of commercial areas, walkways, green courtyards, and other functions; and the segregation of pedestrian and vehicle functions. (ii) At the three-dimensional level, the project must make reasonable planning of shallow, medium, and deep underground space in the industrial zone. Of note, the shallow space can be equipped with municipal integrated pipe corridors, underground commerce, and underground parking. The middle space can be equipped with urban underground rail transit, underground garbage treatment facilities, and underground power stations. In deep space, underground strategic safety reserves, such as underground oil and gas depots and underground arsenals, can be arranged [30]. (iii) At the four-dimensional level, owing to the irreversibility of underground space development [30], we should rely on flexible design thinking to build an open underground space structure. Thus, comprehensive urban planning and underground space development and utilization characteristics are needed to enhance the functionality, adaptability, and scalability of the underground space in industrial areas [31] to fulfill the needs of future urban development. (iv) At the fivedimensional level, old industrial areas often play a pivotal role in the development of cities in the past; they constitute the collective memory of people in the area. In the renewal of the old industrial zone, the memory of the place is the site's soul, recording the historical context of the site, witnessing the past and present of the site, and acting as the link between the public and the site [32]. Thus, in the process of underground space development in industrial areas, thinking about the memory of the place is essential. People should make full use of their unique memories and emotions of industrial areas, as only then the value of the place can be realized in a real sense.

6.4. The Underground Space of the Industrial Areas Integrates High-Tech Industries. The old industrial area is representative of the past urban development history, and getting high-tech is representative of the contemporary advanced life. Integrating technology into underground space development in industrial areas can not only fulfill people's diversified needs for life experience but also support the social needs of urban sustainable development [33]. Underground space development of industrial areas actively explores new development directions of technology while utilizing the existing technological research results. In addition, underground space development provides experimental sites for high-tech industries. Of note, utilizing high technologies in underground space development can effectively enhance the quality of space, and the experimental data obtained can better promote technological development. Thus, they should eventually form a mutually promoting coupled development model to realize the parallel development of underground space development and technology. The fusion between the underground space of industrial areas and technology can inevitably create unexpected architectural forms, artistic effects, and experience perception.

\section{Conclusions}

Underground space development has become a crucial means of activating the vitality of industrial areas and is an integral part of the transformation of industrial areas in the future. Underground space development in the industrial areas can promote the integration of the industrial areas and the city through the organic connection with the urban development elements and then promote the further development of the city.

(1) Underground space development in the starting area reactivates four urban development elements (population, land, economic activities, and public resources), which is of great significance to promote the sustainable development of old urban areas

(2) In the development process of the underground space in the starting area, methods like creating vitality space, enhancing land use efficiency, expanding public resource construction space, and actively using innovative technologies are used, which have reference significance for promoting urban development, endorsing environmental protection, and improving scientific and technological innovation. Moreover, they can be promoted and used in the development of similar projects

(3) The analysis of the underground space project in the starting area can help summarize the development strategy of the integration of the coastal industrial area and the city based on the underground space development; that is, the development of the whole society under the guidance of the government, demonstration on the necessity and feasibility of underground space development in industrial areas, multidimensional development of the underground space in industrial areas, and the underground space of industrial areas integrating high tech

This study has some limitations. First, we only analyzed the underground space development project of the Qingdao Cruise Port starting area from a macro perspective, which lacks the first-person microscopic perspective to analyze the project. Second, the strategies obtained have some limitations. In the future, research in the related fields should be strengthened and constantly explore and innovate to fulfill the needs of the underground space in industrial areas and urban development.

\section{Data Availability}

The data used to support the findings of this study are available from the corresponding author upon request. 


\section{Conflicts of Interest}

The authors declare that they have no conflicts of interest. The authors are employed at the College of Architecture and Urban Planning, Qingdao University of Technology.

\section{References}

[1] Z. Hehua, L. Xiao, P. Fangle, L. Xiaojun, and L. Chunyan, "Development strategy on urban underground space planning in China," Chinese Journal of Engineering Science, vol. 19, no. 6, pp. 12-17, 2017.

[2] W. Guofu, Research on the development and utilization strategy of underground space in existing industrial zones from the perspective of urban renewal, [M.S. thesis], China University of Mining and Technology, 2020, https://kns.cnki.net/KCMS/ detail/detail.Aspx?Dbname $=$ CMFD202101\&filename $=$ 1020817204.Nh.

[3] W. Yaoyu, "Research on underground space planning strategy in the renewal of urban historical waterfront industrial zone-- taking Hangzhou Dacheng north demonstration zone as an example," Chinese and Foreign Architecture, no. 6, pp. 102-105, 2020.

[4] J. Xiang, "Prospects for comprehensive planning and renovation technology of underground space in existing urban industrial zones," Journal of Jiangsu Institute of Architecture and Technology, no. 1, pp. 1-6, 2019.

[5] Z. Haifeng, Research on the demand forecast of underground space development in the industrial zone of existing cities, [M.S. thesis], China University of Mining and Technology, 2020, https://kns.cnki.net/KCMS/detail/detail.aspx?dbname= CMFD202101\&filename $=1020817212 . \mathrm{nh}$.

[6] M. Liantai, "Comprehensive utilization of underground space," Urban Planning, no. 5, pp. 57-59, 1979.

[7] N. Bihua, "Comprehensive development of underground space in urban design," Underground Space, no. 2, 1992.

[8] X. Sishu, "Architectural considerations of underground space," Underground Space, no. 5, pp. 54-69, 1982.

[9] Q. Qihu, "Sustainable urban development and underground space development and utilization," Underground Space, no. 2, pp. 69-74, 1998.

[10] T. Linxu, "Urban intensive development and underground space development and utilization," Underground Space, no. 2, 1998.

[11] S. Yu, P. Fangle, W. Xuan, and Z. Hehua, "Research and practice of urban underground space planning in China," Chinese Journal of Underground Space and Engineering, no. S1, pp. 1125-1129, 2006.

[12] X. Hui, L. Xiaozhao, and C. Jing, "Research on the functional ratio of underground space development at different stages," Chinese Journal of Underground Space and Engineering, no. 3, pp. 573-580, 2016.

[13] Y. Hong and S. Zhongwei, "Research on the evolution of underground space function and the development process of design theory," Architectural Journal, no. 12, pp. 77-82, 2016.

[14] W. Rui, L. Xiaozhao, and W. Jiachen, "Research on the psychological environment influencing factors of underground space workers," Chinese Journal of Underground Space and Engineering, no. 1, pp. 1-8, 2019.
[15] F. Ya and X. Chengli, "Challenges and optimization of the psychological environment of urban underground space," Chinese Journal of Underground Space and Engineering, no. S2, pp. 499-507, 2019.

[16] Y. Ruiying, A study on the impact of urban development factors agglomeration on housing prices, [M.S. thesis], Chongqing University, 2017, https://kns.cnki.net/KCMS/ detail/detail.aspx?dbname $=$ CMFD201801\&filename $=$ 1017837542.nh.

[17] C. Yan, J. Bo, C. Nanchen, C. Shunli, and L. Zirui, "Urban land use efficiency and new urbanization index selection and system reconstruction," China Agricultural Resources and Regionalization, no. 3, pp. 67-75, 2021.

[18] C. Liqiang, "Promoting the construction of people's cities with high quality," Study Times, vol. 4, 2021.

[19] W. Kai, "The home port area of cruise ships from the perspective of the common people," Qingdao Daily, vol. 13, 2020.

[20] Q. Menghai, Research on the spatial promotion and reuse strategy of existing urban industrial zones in Foshan City [M.S. thesis], South China University of Technology, 2020, https://kns .cnki.net/KCMS/detail/detail.aspx?dbname= CMFD202101\&filename $=1020332543 . n h$.

[21] Y. Xu and X. Chen, "Quantitative analysis of spatial vitality and spatial characteristics of urban underground space (UUS) in metro area," Tunnelling and Undesrground Space Technology, vol. 111, article 103875, 2021.

[22] Y. Chunxia, L. Chengzhe, and G. Zhuoxing, "The creation of urban characteristics and vitality," Urban Architecture, no. 1, pp. 144-150, 2019.

[23] W. Hanbin, Research on the development strategy of underground space in high-density urban areas, [Ph.D. thesis], Tianjin University, 2013, https://kns.cnki.net/KCMS/detail/detail .aspx ?dbname $=$ CDFD1214\&filename $=1014036115 . \mathrm{nh}$.

[24] J. Cui, W. Broere, and L. Dong, "Underground space utilisation for urban renewal," Tunnelling and Underground Space Technology, vol. 108, article 103726, 2021.

[25] Q. Qihu, "Welcome climax of urban underground space development in my country," Chinese Journal of Geotechnical Engineering, no. 1, 1998.

[26] Z. Yong and L. Shan, "Financial development, technological innovation and smart city construction: an analysis based on the perspective of information development," Financial Research, no. 2, pp. 4-15, 2016.

[27] F.-L. Peng, Y.-K. Qiao, S. Sabri, B. Atazadeh, and A. Rajabifard, "A collaborative approach for urban underground space development toward sustainable development goals: critical dimensions and future directions," Frontiers of Structural and Civil Engineering, vol. 15, no. 1, pp. 20-45, 2021.

[28] L. Xianjue, Modern Architectural Theory, China Construction Industry Press, 2008.

[29] Y. Xinhua, H. Guangyao, W. Qiangxun, and Z. Lei, "Current status and development trend of urban underground space utilization in my country," Tunnel Construction, no. 2, pp. 173-188, 2019.

[30] Q. Qihu, "Utilizing underground space to help develop green buildings and green cities," Tunnel Construction, no. 11, pp. 1737-1747, 2019.

[31] W. Haibin, "Development and utilization of urban underground space from the perspective of green ecological architecture," Urban Housing, no. 4, pp. 20-22, 2019. 
[32] Z. Jiali, "Design and research on the exterior environment renovation of the old industrial zone based on place memory, [M.S. thesis]," Xi'an University of Architecture and Technology, 2017, https://kns.cnki.net/KCMS/detail/detail.aspx?dbname= CMFD201801\&filename=1017736059.nh.

[33] F. Cuixiao and W. Lei, "Analysis of the prospects of science and technology empowering the construction of people's cities in the future," Zhangjiang Science and Technology Review, no. 6 , pp. $58-61,2020$. 